\title{
Morphological Analysis of Proximal Gastrocnemius Muscle - A Study in Thirty Adult Human Cadavers
}

UPASNA, AMANDEEP SINGH NAR, ASHWANI KUMAR, ATUL MISHRA, ASHVIND BAWA

\section{ABSTRACT}

Introduction: The calf mussles are formed by large gastrocnemius muscle and smaller soleus muscles. The "belly" of calf muscle is an example of fusiform muscle. It is formed by gastrocnemius muscle which is having two heads called caput mediale and caput laterale. The present study of proximal attachments of heads of gastrocnemius muscles in thirty adult human cadavers was done to discuss surgical relevance of morphological variations in the origin of gastrocnemius. Correlation of length of muscle belly with the muscle flaps for defects over anterior tibia and knee joint has been discussed.

Aim: To discuss surgical relevance of morphological variations in the origin of gastrocnemius.

Materials and Methods: Material comprised of 60 lower limbs belonging to 30 embalmed adult cadavers of known sex obtained from Government Medical College, Amritsar. The muscles of posterior compartment of leg were exposed by dissection steps provided by Cunningham's manual of practical anatomy. Origin of both the heads was traced as well as their lengths were taken. An attempt was made to explain the variants.

Results: There was musculotendinous origin from the posterior aspect of head of fibula (6.6\%), fibres were merging with the fibres of plantaris in $13.3 \%$ cases, however, its origin was not from the lateral supracondylar line in $3.3 \%$ cases. Sesamoid bone was observed within proximal attachment of lateral head of Gastrocnemius in $13.3 \%$ caeses. Fibres of medial head of gastrocnemius were observed to have an origin from fascia over Adductor magnus in $6.6 \%$ cases. Medial head was normal in origin in rest of the limbs. The medial head was longer than the lateral head in $48(80 \%)$ limbs with an average length of $16.25 \mathrm{~cm}$.

Conclusion: Anomalous proximal attachments of Gastrocnemius muscle and accessory slips can be there at the level of knee joint. Both MRI and ultrasound can detect anatomical variants. Length of muscle bellies can be a useful guide to the surgeon performing myocutaneous flaps and limb salvage procedures around knee joint. be a useful guide to the surgeon performing myocutaneous flaps and limb salvage procedures around knee joint.

\section{INTRODUCTION}

Gastrocnemius muscle forms the 'belly' of the calf and arises by two heads called caput mediale and caput laterale [1]. Medial head is larger and arises by strong tendon. It arises from the depression on the upper and posterior part of the medial condyle behind the adductor tubercle, slightly raised area on the femoral popliteal surface proximal to the medial condyle, the subjacent areas of the articular capsule and the anterior surface of aponeurosis covering the head. Lateral head arises from an impression on the upper and posterior part of the lateral surface of the lateral condyle of femur, lower part of the lateral supracondylar line of femur and anterior surface of the aponeurosis covering the head [2]. Study of proximal attachments of heads of Gastrocnemius muscle in thirty adult human cadavers was done to discuss surgical relevance of morphological variations in the origin of gastrocnemius. An attempt has been made to discuss embryological basis of these variations.

\section{MATERIALS AND METHODS}

It was an evidence based study, comprised of 60 lower limbs belonging to 30 embalmed adult cadavers of known sex obtained from the Anatomy Department of Government Medical College, Amritsar during June 2004 - 2007. The cadavers were labeled from one to thirty with suffix $R$ (right) or $\mathrm{L}$ (left) and $\mathrm{M}$ (male) or $\mathrm{F}$ (female). The muscles of posterior compartment of leg were exposed as per the dissection steps provided by Cunningham's manual of practical anatomy [3]. Origin of both the heads of Gastrocnemius muscle were traced. Any sesamoid cartilage or bone under the medial or lateral head was noted. Length of both the heads was taken separately up to the common junction of two heads starting from transverse line passing through initial starting point of the muscle heads. The length was measured with the help of a thread and measuring tape. Any other head of origin was specially looked for. Nerve supply of the muscle was traced up to its parent nerve. Any variation from the 
normal pattern was photographed wherever felt necessary. The observations were noted and compiled, analyzed and compared with the standard textbooks and other accessible literature for variant pattern of muscle of the posterior compartment of the leg. An attempt was made to explain the variants wherever possible, on the basis of established developmental stages of the muscles as described in the accessible literature.

\section{RESULTS}

In the present study origin of the lateral head of Gastrocnemius was normal in 38(64\%) limbs and the origin of medial head was normal in 56(93.3\%) limbs. The lateral head showed more number of variations in its origin as compared to medial head. In the present study average length of lateral head was $14 \mathrm{~cm}$ (Range 6.5 to $21.5 \mathrm{~cm}$ ). Length of maximum cases (18 limbs) was within 8.6 to $10.5 \mathrm{~cm}$. In female cadavers $50 \%$ of lateral heads were in range of 12.6 to $14.5 \mathrm{~cm}$. Average length of medial head was $16.25 \mathrm{cms}$ [Table/Fig-1-3]. The medial head was larger than the lateral head in 48(80\%) limbs.

Statistical analysis was not attempted because of small sample size of female cadavers (2) as compared to male cadavers (28).

\begin{tabular}{|c|l|c|}
\hline S. No. & Variations observed & $\mathrm{n}(\%)$ \\
\hline 1 & $\begin{array}{l}\text { Musculotendinous origin from the } \\
\text { posterior aspect of head of fibula (Fig 1,2) }\end{array}$ & $4(6.6 \%)$ \\
\hline 2 & $\begin{array}{l}\text { Fibres merging with the fibers } \\
\text { of Plantaris (Fig 3) }\end{array}$ & $8(13.3 \%)$ \\
\hline 3 & $\begin{array}{l}\text { Origin not from the lateral } \\
\text { suprocondylar line }\end{array}$ & $2(3.3 \%)$ \\
\hline 4 & $\begin{array}{l}\text { Sesamoid bone in lateral head } \\
\text { of Gastrocnemius (Fig 4) }\end{array}$ & $8(13.3 \%)$ \\
\hline
\end{tabular}

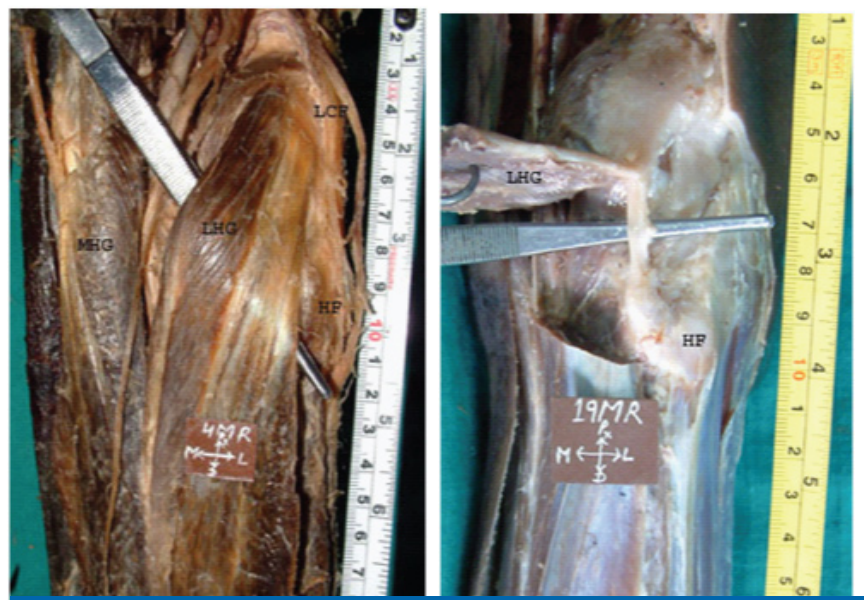

\begin{tabular}{|c|l|c|}
\hline S. No. & Variations observed & $\mathrm{n}(\%)$ \\
\hline 1 & $\begin{array}{l}\text { Fibres coming from fascia covering } \\
\text { Adductor magnus }\end{array}$ & $4(6.6 \%)$ \\
\hline
\end{tabular}

[Table/Fig-2]: Variations observed in the origin of Medial head of Gastrocnemius.

\begin{tabular}{|l|c|c|}
\hline Length & Lateral head & Medial head \\
\hline Minimum length & $6.5 \mathrm{~cm}$ & $8.0 \mathrm{~cm}$ \\
\hline Maximum length & $21.5 \mathrm{~cm}$ & $24.5 \mathrm{~cm}$ \\
\hline Average & $14.0 \mathrm{~cm}$ & $16.25 \mathrm{~cm}$ \\
\hline
\end{tabular}

\section{DISCUSSION}

In our study 4(6.6\%) cases showed musculotendinous origin from the posterior aspect of head of fibula [Table/ Fig-4,5]. Gastrocnemius consists of blended factors of the caudopedal and of the superficial layer of pronatoflexor mass, some of which - the soleus elements - pass from the fibula, with occasionally factors from, or a connection with, the caudofemoral. Most of these descend from the fibular side of the limb [4]. As some of the soleus elements did not differentiate from gastrocnemius and remained with the original muscle mass, we encountered musculotendinous origin from posterior aspect of head of fibula. Phylogenitically the medial head of gastrocnemius has been suggested to be medial extension from the fibular head.

In many mammals, it is not differentiated (Several edentates, carnivora, etc.,) [5]. In 8 cases (13.3\%) fibres of gastrocnemius were merging with fibres of plantaris muscle [Table/Fig-6]. Here, some of the fibres of plantaris may not have been differentiated from the deeper portion of gastrocnemius muscle.

In $2(3.3 \%)$ cases, origin of gastrocnemius was not from the lateral supracondylar line. In an embryo of $20 \mathrm{~mm}$, the lateral head of gastrocnemius has formed a tendinous attachment
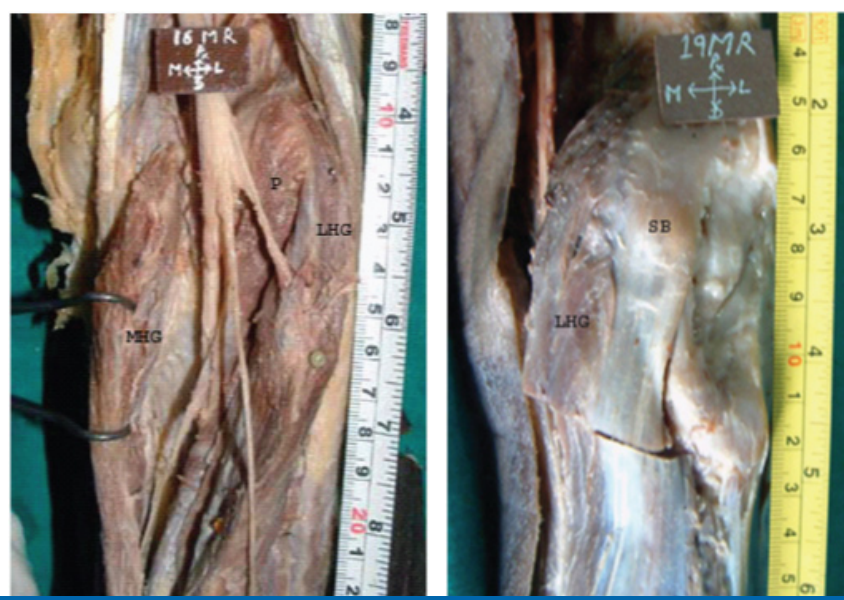

[Table/Fig-4]: Origin of lateral head of gastrocnemius muscle ( LHG) from lateral surface of lateral condyle of femur (LCF) and head of fibula (HF). [Table/Fig-5]: Fibres of lateral head of gastrocnemius muscle (LHG) coming from the head of fibula (HF). [Table/Fig-6]: Lateral head of gastrocnemius muscle (LHG) merging with plantaris muscle (P). [Table/Fig-7]: Sesamoid bone (SB) in the lateral head of gastrocnemius muscle (LHG) - fabella. 
above the lateral condyle of femur while the medial head has not yet quite reached its final destination [5]. Thus, this variation found in our study can be due to failure of formation of tendinous attachment above the lateral condyle of femur at $20 \mathrm{~mm}$ stage of embryo.

In one study the fabella that is small sesamoid located within lateral head of gastrocnemius was present in $10-20 \%$ of population [6]. In present study, the sesamoid bone in lateral head (Fabella) was found in $13.33 \%$ cases [Table/Fig-7] which is in consonance with Parsons and Keith [7], Pearson and Pavin [8] and Le Minor [9]. There was no sesamoid bone found in medial head of gastrocnemius. Local mechanical forces associated with skeletal geometry, posture and muscular activity are related with development of fabella. It may be linked to intrinsic genetic factors. Presence of a fabella (Sesamoid bone in lateral head of gastrocnemius) in humans has been linked to primary osteoarthritis of the knee joint as said by Pritchet [10] and Hessen [11]. In our study average length of medial head of gastrocnemius muscle was $16.25 \mathrm{~cm}$ and of lateral head was $14 \mathrm{~cm}$. Magdyel-Sherbiny studied the length of heads of gastrocnemius and area covered by myocutaneous flaps. In their study medial head of gastrocnemius muscle measured 15 to $20 \mathrm{~cm}$ in length. The length of lateral head of gastrocnemius muscle measured 12 to $17 \mathrm{~cm}$. The corresponding skin territory of each head measured $23 \mathrm{~cm}$ in length. They concluded that the area of potential wound closure is greater for the myocutaneous flap than for the muscle flaps alone [12]. Lateral gastrocnemius, is smaller in size than its medial counterpart, however it satisfactorily covers the laterally located defect over anterior tibia and knee joint [13]. The best imaging technique that should be used for detection and appropriate diagnosis of accessory slips of the medial and lateral heads of gastrocnemius muscle is MRI due to deep location of the structures to be evaluated [14]. Our study can be helpful to the researchers working in the fields of orthopedics, plastic surgery and kinesiology. Further study should be done in Indian population to know the relation between postural habits and morphology of gastrocnemius muscle.

\section{CONCLUSION}

Gastrocnemius muscle variations are more common than normally thought. Variations of origin of gastrocnemius consist of anomalous origins and accessory slips at the level of knee joint. Anatomical variants related to the accessory musculature are detected more commonly with the increased use of both ultrasound and MRI. Variations in the proximal attachments of gastrocnemius should be known to the surgeon performing myocutaneous flaps and limb salvage procedures around knee joint.

\section{REFERENCES}

[1] Kadir D, Ceren U, Busra S, Esra K and Ali MM. A study on the structure and morphologic development of calcaneal tendon and triceps surae muscle in human fetuses during the fetal period and the evaluation of clinical importance of calcaneal tendon. Int. J. Morphol. 2015; 33(3):920-29.

[2] Williams PL, Bannister LH, Berry MM, Collins P, Dyson M, Dussek JE. Skeletal system and muscle, In: Gray's Anatomy, $38^{\text {th }}$ ed, Churchill Livingstone, New York 1995; 868-900.

[3] Romanes GJ. Muscles of the leg and foot.In: Cunningham's textbook of Anatomy, $10^{\text {th }}$ Edn. Oxford University Press, London-NewYorkToronto.1964;360-67.

[4] Humphry. On the disposition of muscles in vertebrate animals. J Anat Physiol. 1872;6:360.

[5] Bardeen CR. Development and variation of the nerves and the musculature of the inferior extremity and of the neighboring regions of the trunk in man. Am J Anat. 1907; 6:259-390.

[6] Bergman AG (September 2013) Proximal Gastrocnemius tendon pathology. In MRI web clinic. Available via RADSOURCE. http://radsource.us/proximalgastrocnemius-tendon-pathology/. Accessed 17 Dec 2014

[7] Parsons FG and Keith A. The presence of sesamoid bodies in either head of the gastrocnemius and in the tendon of peroneus longus. $J$ Anat Phys. 1897;32:182-86.

[8] Pearson K and Pavin AG. On the sesamoids of the knee joint. I. Man II Evolution of the sesamoids. Biometrica. 1921;13:133-175,350-400.

[9] Le Minor JM. Comparative anatomy and significance of sesamoid bone of the peroneus longus muscle (os perineum). J Anat.1987:151:85-99.

[10] Pritchet JW. The incidence of fabellae in osteo arthritis of the knee. J Bone Joint Surg. 1984;66-A:1379-80.

[11] Hessen I. Fabella: sesamum genu superius laterale. Acta Radiol. 1946;27:177-96.

[12] El-Sherbiny M. Pedicled gastrocnemius flap:Clinical application in limb sparing surgical resection of sarcoma around the knee region and popliteal fossa. J Egypt Natl Canc Inst. 2008;20(2):196-207.

[13] Khan AH, Ahmed QG. Gastrocnemius muscle flaps for coverage of knee and upper tibial defects. Indian j orthop. 2003:37(1):12.

[14] Tagliafico A, Bignotti B, Airaldi S, Martinoli C. Correlation of Skeletal Muscle Anatomy to MRI and US Findings. In: Weber MA, editor. Magnetic Resonance Imaging of the Skeletal Musculature. Berlin Heidelberg: Springer; 2014. pp. 27-39.
AUTHOR(S):
1. Dr. Upasna
2. Dr. Amandeep Singh Nar
3. Dr. Ashwani Kumar
4. Dr. Atul Mishra
5. Dr. Ashvind Bawa

\section{PARTICULARS OF CONTRIBUTORS:}

1. Associate Professsor, Department of Anatomy, Government Medical College, Patiala, India.

2. Assistant Professor, Department of Surgery, Dayanand Medical College and Hospital, Ludhiana, India.

3. Professor, Department of Surgery, Government Medical College, Patiala, India.
4. Professor, Department of Surgery, Dayanand Medical College and Hospital, Ludhiana, India.

5. Assistant Professor, Department of Surgery, Dayanand Medical College and Hospital, Ludhiana, India.

\section{NAME, ADDRESS, E-MAIL ID OF THE CORRESPONDING AUTHOR:}

Dr. Upasna,

Associate Professsor, Department of Anatomy, Government Medical College, Patiala, Punjab-147001, India.

E-mail: ashwaniupasna@yahoo.com

FINANCIAL OR OTHER COMPETING INTERESTS: None.

Date of Publishing: Apr 01, 2016 